\title{
2013: another good year for EJNMMI
}

\author{
Ignasi Carrió
}

Published online: 31 October 2013

(C) Springer-Verlag Berlin Heidelberg 2013

Dear readers,

Thanks to the continuing support of our editors, editorial board members, numerous expert reviewers, and the editorial team at Springer, EJNMMI has continued to advance in 2013. The journal has received an increasing number of original manuscripts, with over 1300 submissions of original articles expected by the end of the year (an increase of almost $20 \%$ over 2012). The impact factor (IF) rose to 5.114 for 2012, the highest ever, and the highest in Europe for the entire field of medical imaging. The impressive number of full-text downloads (> 430,000 in 2012) reflects the influence of the journal on clinical practice and research. I am grateful to our authors, reviewers, editors and staff for helping us to make EJNMMI a prime journal in nuclear medicine and molecular imaging.

\section{Growing the EJNMMI journal family}

The EJNMMI started in 1976 (as EJNM) with a modest number of submissions and without an IF. Over the years the EJNMMI has made it into the top five journals worldwide in the field of medical imaging according to the various ISI metrics. As a consequence, the journal has experienced an ever-increasing number of submitted manuscripts, while the acceptance rate has declined significantly. Often space restrictions in the journal have precluded acceptance of interesting manuscripts that have then been submitted and eventually published elsewhere. As such manuscripts have value for doctors and scientists working in the field of nuclear medicine and molecular imaging, the creation of a family of EJNMMI journals became a necessity, starting by the launch

I. Carrió $(\bowtie)$

Nuclear Medicine Department, Hospital Sant Pau, Barcelona, Spain

e-mail: icarrio@santpau.cat of EJNMMI Research in 2011, under the leadership of Angelika Bischof Delaloye. Fortunately, EJNMMI Research has brought additional opportunities for publication of articles on clinical and basic research, in particular for those that address very technical issues or are focussed on basic research in our field. At the end of this year, the second companion journal is being launched: EJNMMI Physics, under the leadership of Thomas Beyer, will offer ample space and new opportunities for articles with a strong focus on physics and related areas. Authors may submit their original work directly to any of the journals in the EJNMMI family. In addition, papers considered less suitable for publication in the main journal after peer review may be eligible for transfer to EJNMMI Research or EJNMMI Physics. In such cases, the authors will be offered the opportunity to resubmit to the companion journal, where they may find a fast option for review and eventual publication of their work. We look forward to these new journals having significant IFs in the near future.

\section{Manuscript selection and published items}

As EJNMMI has a current acceptance rate of $19 \%$, manuscript selection is becoming increasingly challenging. Sometimes an immediate decision to decline a paper is taken at the editorial office ( $22 \%$ of submissions in 2013), particularly when the subject of the article is out of the scope of the journal or the paper is judged to be better suited for a different journal. When an article is considered suitable for EJNMMI, at least two reviewers are invited within 2 days, with over 3000 peer experts invited to review for EJNMMI in 2013. Although the advantages of peer review are obvious, the process is not without potential danger. Is the reviewer really an expert? Is the reviewer biased? May the article challenge his or her favourite hypothesis? Are there financial issues?, 
etc. All theses issues become especially relevant with decreasing acceptance rate. To improve the process, EJNMMI rates the reviewers and carefully evaluates the quality of the review and potential conflicts. The novelty and potential overlap with previous publications is checked prior to acceptance, to ensure that we select the most innovative and interesting papers from the many articles that have been submitted. We thank all authors for, almost always, accepting all criticisms in a positive and constructive way.

The articles published in 2013 include 22 Editorials, 185 Original Articles, 10 Review Articles, 17 Images of the Month, 14 Letters, 3 Guidelines and 7 Book Reviews. In addition, the current practice for diagnosing primary and recurrent prostate cancer, and the future role of multimodal imaging, including PET/MR, were presented in a supplement on prostate cancer imaging [1], edited by Maria Picchio and Morand Piert. All these 2013 EJNMMI publications resulted in thousands of full-text hits on the journal's website. The IF is deemed to reflect the influence of a given journal on the scientific community, but may not reflect the true relevance of the published materials for clinical practice. The very high number of downloads may be a better indicator of the influence of the journal on the profession and its relevance for the professional practice of nuclear medicine. Finally, all of us search for scientific information more and more on the net rather than in printed articles or in textbooks. Most readers like to receive publications on their iPhone, iPad or laptop. To keep up with this need EJNMMI is now electronically available as an App through http://itunes.apple.com and http://play.google.com.

\section{Are we making an impact?}

The EJNMMI 2012 IF rose to 5.114 (2,327 citations of 455 articles, with $14 \%$ of self-cites), the highest ever, and the highest in Europe in the entire field of medical imaging. Our immediacy index (Citations to articles published in the same year) was 1.202, reflecting easier and more rapid online access to the EJNMMI articles. The cited half-life (number of publication years from the current year which account for $50 \%$ of current citations) is 5.8 years and the total number of citations increased to 10,881. The Eigenfactor Score was 0.02738 and the Article Influence Score was 1.393, among the highest in the field (Thompson Institute for Scientific Information's Journal Citation Reports).

With regard to journal performance in 2013, the average time from submission to technical check complete has been 1.6 days, submission to reviewer invitation 2.2 days, and submission to first decision 18.7 days. The average time from submission to final acceptance has been 65 days (including revision, re-submission and re-evaluation) and that from submission to rejection 28 days. Such times are made possible by the rapid in-house processing of all manuscripts and the prompt and careful reviews provided by most of the expert reviewers.

The annual EJNMMI awards are intended to acknowledge excellence in the published clinical and basic research and are delivered at the closing ceremony of the EANM congress, this year held in Lyon. An article reporting on the comparison of bone scintigraphy with 11C-choline PET in bone metastasis from prostate carcinoma by Maria Picchio and colleagues [2] was named best clinical paper of 2012. The best basic science paper in 2012 was on PET imaging of CD105 expressions with Zr-89-Df-TRC105, by Hong Hao and colleagues [3]. The EJNMMI article cited most often in 2012 (publication in 2009, Citations between 2010 and 2012) was a paper on PET changes in brain glucose metabolism from normal cognition to Alzheimer's disease by Lisa Mosconi and colleagues [4]. The annual highlights lecture was given by Prof. Stefano Fanti and Prof. Frank Bengel, who performed with an unforgettable mix of humour, clever comments and scientific vision. They will soon author a Review Article summarizing the highlights of the congress and the major scientific contributions reported in Lyon. Many excellent abstracts presented during the congress may result in original manuscripts which, as Editor, I will be eager to receive and possibly publish after appropriate peer review. Interestingly, a recent analysis to determine predictors of acceptance and future publication [5] showed that abstracts on basic science, clinical abstracts including at least 100 patients, and those with a prospective study design were most likely to be accepted for publication as full articles in high-ranking journals.

Just a final note of thanks to our dedicated editorial team: Carmina Jimenez, my always-online editorial assistant who handles communication and correspondence with authors and reviewers (circa 40,000 letters generated in 2012 !); David Roseveare, who takes care of the production process; Claudia Schiffers, who is in charge of the journal's busy website and online system, and Sabine Ben Ghechir, who coordinates Springer's office in Heidelberg. Dear colleagues and readers, I hope that the European Journal of Nuclear Medicine and Molecular Imaging will continue to advance in the coming year, and wish you all a very successful and scientifically productive 2014!

Ignasi Carrió

EJNMMI Editor-in-Chief

\section{References}

1. Picchio M, Piert M. Prostate Cancer Imaging. Eur J Nucl Med Mol Imaging. 2013;409 Suppl 1:S1-4. 
2. Picchio M, Spinapolice EG, Fallanca F, et al. [C-11]Choline PET/CT detection of bone metastases in patients with PSA progression after primary treatment for prostate cancer: comparison with bone scintigraphy. Eur J Nucl Med Mol Imaging. 2012;39(1):13-26.

3. Hong H, Severin GW, Yang Y, et al. Positron emission tomography imaging of CD105 expression with Zr-89-Df-TRC105. Eur J Nucl Med Mol Imaging. 2012;39(1):138-48.
4. Mosconi L, Mistur R, Switalski R, et al. FDG-PET changes in brain glucose metabolism from normal cognition to pathologically verified Alzheimer's disease. Eur J Nucl Med Mol Imaging. 2009;36(5):811-22.

5. Winnik S, Speer T, Raptis DA, Walker JH, Hasun M, et al. From abstract to impact in cardiovascular research: factors predicting scientific quality. Eur Heart J. 2012;33:3034- 45. 